\title{
Experimental Research on Application of the Natural Light to Tunnel Lighting Engineering
}

\author{
Bao-Lin WANG*, Ying YE and Bingya YAN \\ Hunan Communications Research Institute; Research and Promotion Center for Energy-Saving and Emission-Reduction \\ Technology of Hunan Transportation, Changsha, Hunan 410015, China
}

Received May 26, 2014, Accepted January 29, 2015

\begin{abstract}
In present paper, the natural light was led into the entrance section of a highway tunnel by the specially designed lighting bands, and the lighting luminance profile was modeled referring to the human visual adaptation curve. As the result, the lighting enhanced at the entrance section was completely canceled. In order to validate the current scheme, lighting effects were evaluated by experimental data. In contrast to the conventional schemes, this scheme presented more advantages: (1) Eliminating the "black-hole effect' of tunnel entrance, which significantly improved the driving safety and amenity. (2) The energysaving of lighting was very considerable. (3) The scheme was simple, practical, and reasonable in cost. It could be concluded the application of natural light to tunnel lighting engineering had significant popularization value.
\end{abstract}

KEYWORDS: lighting of highway tunnel, utilization of natural light, energy-saving and emission reduction, black-hole effect, experimental research

\section{Introduction}

With the implementation of the '7918' highway network plan of $\mathrm{China}^{1)}$, highway constructions in the mountain areas have entered into a period of vigorous development. As one of the important parts of highway, tunnel construction quantities and scales were increased year by year in China, since the tunnel has some advantages such as shortening highway mileages, improving transportation efficiency, saving land resources as well as protecting ecological environment. At the end of 2011, a total number of 8522 tunnels with a total length of 6253 kilometers had been built in Chi$\mathrm{na}^{2}$. However, the yearly increased tunnel mileages had brought out a serious social and economic problem. That is the energy consumption of tunnel lighting is very huge, which had become a heavy burden to the operation management department of highway ${ }^{3 / 4)}$. Making the longest highway tunnel in China (Qinling Zhongnanshan tunnel) for example, only the monthly lighting electricity bills of the tunnel can be up to one million or more ${ }^{5}$. Therefore, it could be seen that, how to achieve the energy-saving of tunnel lighting based on the principle of highway driving safety, is an urgent issue needed to be currently resolved by the highway construction and operating management department ${ }^{5 / 6)}$.

At present, ideas researched and applied to resolve the lighting 'energy consumption' problems of tunnel can be roughly divided into the following categories:
The first is optimizing the existed single or multiobjective design parameters of tunnel lighting, such as the luminous intensity, illumination uniformity, light regulating and lamps layout, which are usually used for the traditional high pressure sodium lamps lighting system. For instance, Yang ${ }^{7}$ received a good effect of lighting energy-saving and prolonged the lamps lifetime by decreasing the lamps voltage. This method is relatively simple, but the energy-saving range of lighting is limited. The next is using new types of energy-saving lamps such as the light emitting diode (LED) lamps, electromagnetic induction lamps ${ }^{8}$, and in the meantime, equipping with advanced light intelligent control systems. Yao et al." obtained excellent energy-saving by applying LED lamps to tunnel lighting separated at the time of day and night. Wang and Zhou ${ }^{10)}$ got a good effect of energy-saving, by using the intelligent light stepless regulating system of LED lamps to urban tunnel. Nagai et al. ${ }^{11)}$ also received a considerable amount of lighting energy saving using a construction method. Although these methods generated considerable effects of lighting energy-saving, however, the maturity and reliability of key technologies such as the heat dissipation, light decay and interchangeability of lamps still needed to be further improved. Moreover, these new types of energy-saving lamps are prevented from applying widely due to their higher prices. The final one is the use of new energy such as the solar energy, wind en- 
ergy, geothermal energy and so on. For example, Han ${ }^{12)}$ invented an interesting tunnel lighting idea and received a perfect energy-saving of lighting, which supplied the lighting for tunnel alternately by solar energy optical fiber and LED lamps. However, the method is susceptible to the natural factors, and furthermore, the control system is extremely complex so that its reliability and stability are hard to be guaranteed.

In order to evade the technology problems descripted above, and resolve the energy consumption problems of tunnel lighting in essence, a new idea is proposed in present paper ${ }^{13)}$, which is supplying the lighting for the entrance and exit sections of tunnel by the natural light, the main principle of this idea is: extending the entrance and exit sections along the directions outside the tunnel, and then leading the natural light into these extended areas by the lighting bands designed specially, the purpose is to cancel completely the enhanced lighting at the entrance and exit sections, so that significant energy-saving and emission reduction of tunnel lighting will be received. According to "Specifications for Design of Ventilation and Lighting of Highway Tunnel" (JTJ026.1-1999) ${ }^{14)}$, a professional industry standard adopted in China now, the lighting luminance at the entrance, transition, and exit sections of tunnel is designed to be 28,8 , and 5 times of luminance at the middle section, respectively. It can be seen that the contributions of lighting energy reductions at the entrance and exit section is very considerable to the energysaving of the whole tunnel lighting. Therefore, the natural light lighting technology proposed above is applied to a highway tunnel in the following paper, and the application practicability and reliability of the technology will be finally evaluated and analyzed by the experimental data. The final purpose of present paper is to richen the theories domain of lighting energysaving technology used in tunnel, and enhance the engineering application level of natural light lighting technology.

\section{Scheme design of tunnel lighting}

The highway tunnel which the natural light lighting scheme applied to is $651 \mathrm{~m}$ in length and $8 \mathrm{~m}$ in net height, and is designed to be unidirectional including 3 lanes. The vehicle speeds designed on 3 lanes are $100 \mathrm{~km} / \mathrm{h}, 80 \mathrm{~km} / \mathrm{h}$ and $60 \mathrm{~km} / \mathrm{h}$, respectively. The tunnel includes a total of $91 \mathrm{~m}$ long entrance section, however, due to the influence of highway project cost, only an existed semitransparent entrance section at the left side of tunnel, with a length of $40 \mathrm{~m}$ can be made use of natural light lighting designs in present paper. Therefore, the lighting scheme designed along this section of tunnel will be introduced in the following paper.

\subsection{Design of the main structural frame}

The main structural frame of natural light lighting system applied to the entrance section of tunnel, can be both designed by the conventional reinforced concrete construction and the popular steel-frame construction. In this paper, the reinforced concrete construction of the tunnel itself was followed to be used. The schematic diagram of natural light lighting construction was shown in Figure 1, which was an arched building, and consisted of reinforced concrete arched beams (2), lighting and ventilating bands (3), a concrete foundation (4), and a reinforced concrete girder at the top (7). Part of natural light outside the arched building was kept out by the arched beams (2) and stainless steel plates, and the other part was led into the tunnel for use of lighting enhanced at the entrance section, by the special lighting glass installed at the lighting bands (3). Figure 2 showed the final installation of the building in scene.

\subsection{Design of the lighting and ventilating bands}

The lighting and ventilating bands (3) are designed by the connections of lighting windows (8), light shutting windows (9), and ventilating holes (10), as seen in the Figure 3. The lighting windows (8) were fully equipped by the frosted glass of the same size, which had strong performances of light scattering, and in the

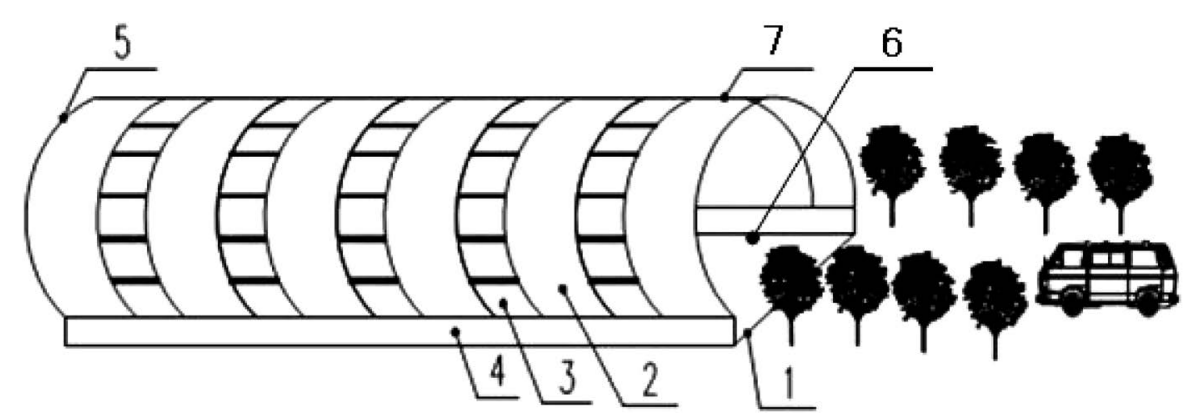

Figure 1 Configuration of natural light lighting system at the entrance section of tunnel. 1) Road surface. 2) Reinforced concrete arched beams. 3) Lighting and ventilating bands. 4) Concrete foundation. 5) End of tunnel entrance section. 6) Tunnel portal. 7) Reinforced concrete girder at the top. 


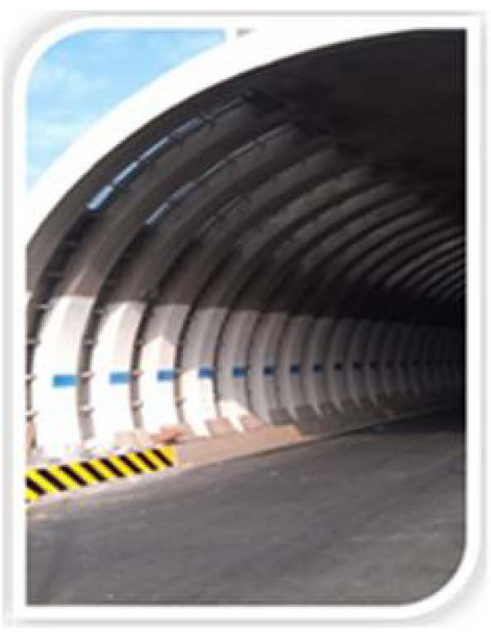

(a) Portal part of the tunnel

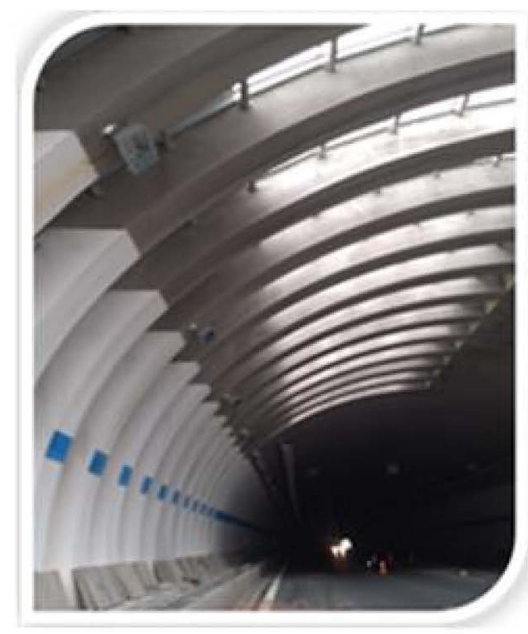

(b) Middle part of the entrance section

Figure 2 Final installation configurations of the tunnel entrance section. (a) Portal part of the tunnel. (b) Middle part of the entrance section.

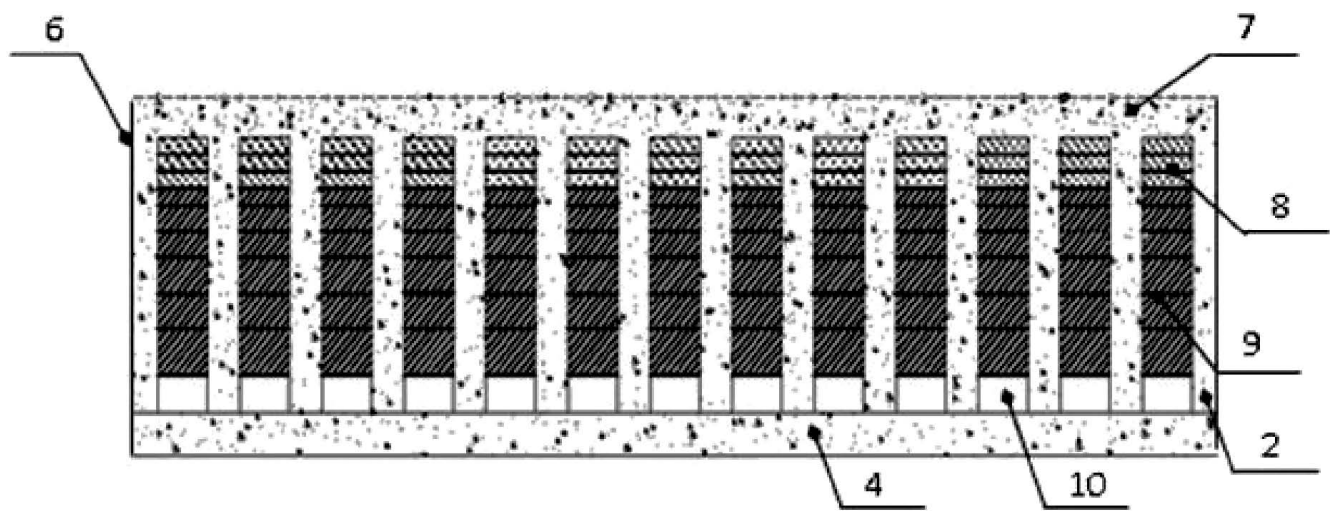

Figure 3 Top view of the designed lighting and ventilation bands. 8) Lighting windows. 9) Light shutting windows. 10) Ventilating holes.

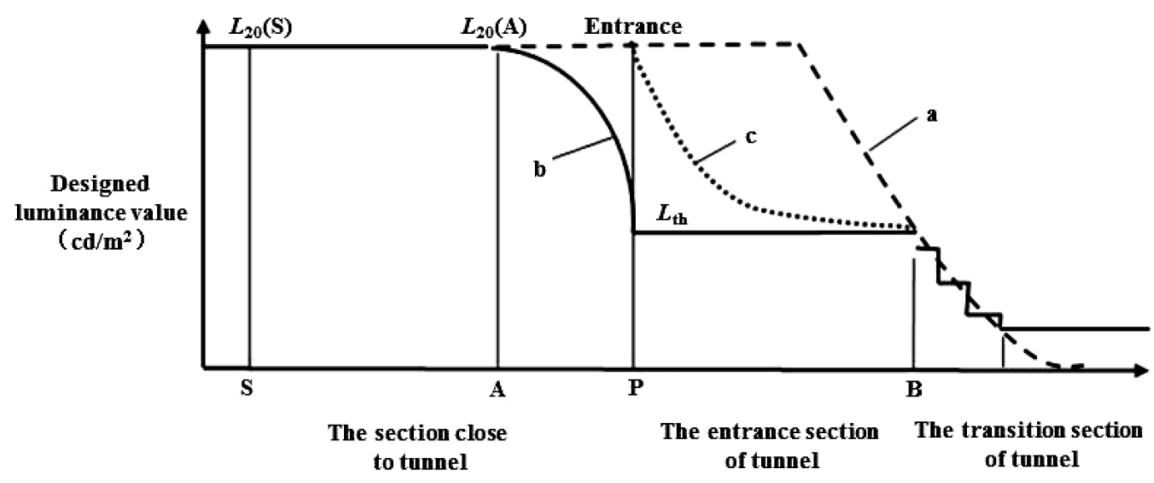

Figure 4 Comparisons of the designed luminance curves at the entrance section of tunnel. a) The human visual adaptation curve ${ }^{14) 15}$. b) The luminance curve lighted by conventional power ${ }^{14)}$. c) The luminance curve lighted by natural light. S) The start point of the section close to tunnel. A) Adaption point. P) Entrance of tunnel. B) The start point of transition section. $L_{20}(\mathrm{~S})$ : Luminance value outside the tunnel. $L_{20}(\mathrm{~A})$ : Luminance value at the location of adaption point. $L_{\mathrm{th}}$ : Luminance value at the entrance section of tunnel. 
meantime, the installation clearances were sealed by asphalt. The light shutting windows (9) were covered by the stainless steel plates, and the gaps were sealed by glass adhesive. The ventilating holes (10) were located at the bottom of light shutting windows (9). Here, one thing must be pointed out, the width of lighting glass between two adjacent arched beams (2) was confirmed, by the reversal calculation of the luminance curve of natural light and light transmission performance parameters of glass. The luminance curve was modeled and fitted by referring to the human visual adaptation curve shown in the Figure 4, which is popularly used internationally ${ }^{1415)}$. It can be seen that the designed lighting luminance profile was approximately parallel to the human visual adaptation curve, so the 'black-hole effect' at the entrance of tunnel was disappeared in essence, which was helpful to ease visual fatigue of drivers, and improve the driving safety and amenity on tunnel road. The human visual adaptation curve used internationally was formulated as follow ${ }^{14) 15}$ )

$$
L_{\text {th }}=L_{20}(\mathrm{~S})(1.9+t)-1.4
$$

where $L_{\text {th }}\left(\mathrm{cd} / \mathrm{m}^{2}\right)$ is the luminance value at different locations of tunnel entrance section. $L_{20}(\mathrm{~S})\left(\mathrm{cd} / \mathrm{m}^{2}\right)$ is the luminance value outside the tunnel hole. $t(\mathrm{~s})$ is the vehicle passing time along the entrance section.

On the other hand, $L_{\text {th }}$ can be calculated by the luminous flux $\Phi$ according to the light transmission principle as follows:

$$
L_{\mathrm{th}}=\mathrm{d} \Phi /[\mathrm{d} \Omega \cdot \mathrm{d} s \cos (\theta)]
$$

where $\Phi(\mathrm{lm})$ is the luminous flux. $\Omega(\mathrm{sr})$ is the solid angle. $\theta$ is the included angle between the given direction and the normal direction of unit area cell ds.

According to the relational expression (1) and (2), the size of lighting bands can be calculated inversely.

\subsection{Layouts of the lighting lamps}

In order to analyze conveniently the energy-saving and emission reduction effects of the natural light lighting scheme applied to the tunnel, a kind of lamp layout for lighting scheme of conventional high pressure sodium lamps, was designed as a baseline for comparison in this paper. According to engineering design requirements of the highway project, the target values of lighting luminance designed at the entrance, first transition, and middle sections of the tunnel were $105 \mathrm{~cd} / \mathrm{m}^{2}, 40 \mathrm{~cd} / \mathrm{m}^{2}$, and $4.5 \mathrm{~cd} / \mathrm{m}^{2}$, respectively. If the conventional high pressure sodium lamps were used for the tunnel lighting, then the corresponding layout scheme of lamps was listed in Table 1 . As seen in the table, $400 \mathrm{~W}$ and $250 \mathrm{~W}$ lamps were used alternately for enhanced lighting at the entrance section, while $100 \mathrm{~W}$ lamps were for emergency lighting. At the middle section, $100 \mathrm{~W}$ lamps were installed symmetrically to two sides of the tunnel, and the space length between two lamps was $6 \mathrm{~m}$. However, after the natural light lighting scheme was applied, except the entrance section, the lamps layouts at the other sections of the tunnel kept the same as the scheme in former. Here, the enhanced lighting at the entrance section with a length of $40 \mathrm{~m}$ was canceled completely, and only $100 \mathrm{~W}$ lamps were remained for both basic lighting at night and emergency lighting, as listed in Table 2.

From the comparison of Table 1 and Table 2, it could be found that lamps power of enhanced lighting at the entrance section was reduced by $28.2 \mathrm{~kW}$, which resulted in an energy-saving rate of $44 \%$, when the natural light lighting scheme was applied to the tunnel. If the power was paid by 1Yuan per hour, and the lighting time enhanced at the entrance section was calculated by $12 \mathrm{~h}$ per day, about 124 thousands Yuan electricity bills per year would be saved. Furthermore, if the early investment costs of lamps and maintenance expenses were included together, the economic benefits created by the natural light scheme were very considerable. Here, one point must be emphasized that due to the influence of highway project cost mentioned ahead, only a length of $40 \mathrm{~m}$ entrance section was designed to be lighted by the natural light, which was even less

Table 1 Lamps layout for the conventional lighting scheme of high pressure sodium lamps

\begin{tabular}{lcccc}
\hline \multicolumn{1}{c}{ Regions } & Length $(\mathrm{m})$ & Type of lamps $(\mathrm{W})$ & Number of lamps & Total power $(\mathrm{kW})$ \\
\hline Entrance section & 91 & $400 / 250 / 100$ & $104 / 78 / 28$ & $41.6 / 19.5 / 2.8$ \\
Transition section 1 & 77 & $250 / 100$ & $66 / 22$ & $16.5 / 2.2$ \\
Transition section 2 & 91 & $250 / 100$ & $26 / 26$ & $6.5 / 2.6$ \\
Middle section & 329 & 100 & 96 & 9.6 \\
Exit section & 63 & $150 / 100$ & 518 & $5.4 / 3.6$ \\
Total & 651 & $/$ & & 110.3 \\
\hline
\end{tabular}

Table 2 Lamps layout for the natural light-high pressure sodium lamps lighting scheme

\begin{tabular}{lcccc}
\hline \multicolumn{1}{c}{ Regions } & Length $(\mathrm{m})$ & Type of lamps $(\mathrm{W})$ & Number of lamps & Total power $(\mathrm{kW})$ \\
\hline Entrance section of natural light & 40 & 100 & 14 & 1.4 \\
Entrance section of power & 51 & $400 / 250 / 100$ & $56 / 42 / 14$ & $22.4 / 10.5 / 1.4$ \\
\hline
\end{tabular}


than half of the total length at entrance section of the tunnel, so the energy-saving potentialities of the tunnel used in present paper were far away from being evacuated completely.

In addition, according to the current level of thermal power plants in China ${ }^{16)}$, which $1 \mathrm{kWh}$ electrical energy producing consumed an average of $360 \mathrm{~g}$ of standard coal, and created emissions of carbon dioxide by $997 \mathrm{~g}$, and sulfur dioxide by $30 \mathrm{~g}$. It could be calculated that a sum of 44.5 tons of standard coal would be saved approximately per year, and in the meantime, a sum of 123 tons of carbon dioxide and 3.7 tons of sulfur dioxide were approximately decreased per year, when the natural light scheme was applied to the tunnel. In summary, the natural light lighting technology used in the paper had created significant energy-saving and emission reduction effects, the social and economic benefits were remarkable.

\section{Experimental evaluations}

In order to further validate the practicability and reliability of the natural light lighting scheme used in this paper, an experiment approach was adopted to evaluate the application effects in scene. The experiment instruments mainly included a XYL-III luminance meter, a LX1010BS illuminometer, a tape measure, pieces of labeling chalk, and a camera.

\subsection{Experiment methodology}

A center-method was used for the experiment ${ }^{17}$, in which the tested roadway was divided to a certain number of rectangular grids with same sizes, and tested points were located at the center of these grids. In current experiment, a number of 21 points was arranged along the driving direction of tunnel entrance section with a length of $40 \mathrm{~m}$, and the interval between two adjacent points was about $2 \mathrm{~m}$. However, a total number of 9 points was arranged at the cross direction of

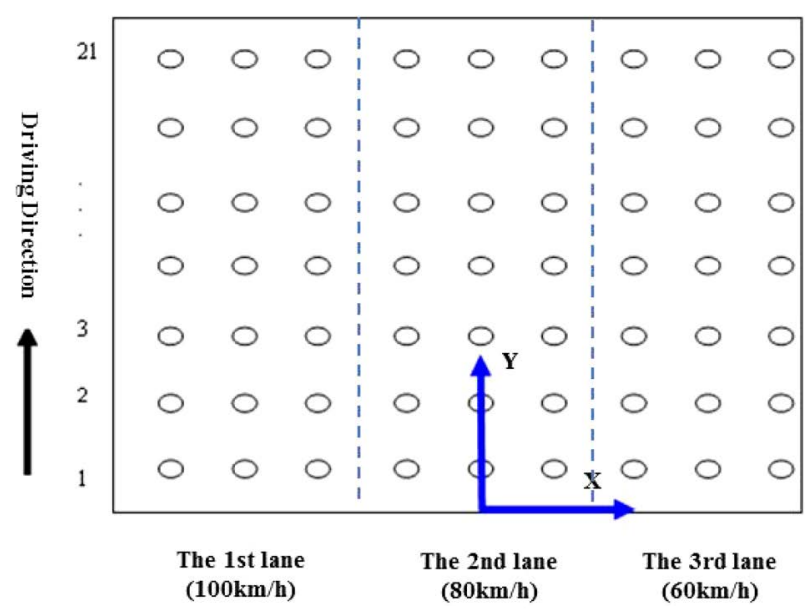

Figure 5 Schematic diagram of layout of experimental points. tunnel, and on each lane, an average of 3 points was set, as seen in the Figure 5. It should be pointed out that the origin of Cartesian coordinates was located at the center of tunnel portal, and the axis $X$ and $Y$ were defined by the transverse direction and driving direction, respectively.

\subsection{Evaluation indicators}

\subsubsection{Luminance value at the entrance section}

According to the professional industry standard of "Specifications for Design of Ventilation and Lighting of Highway Tunnel" (JTJ026.1-1999) ${ }^{14)}$, the luminance values of lighting designed at the entrance section of the tunnel should satisfy the following equation,

$$
L_{\text {th }}=k * L_{20}(\mathrm{~S})
$$

where $L_{\text {th }}\left(\mathrm{cd} / \mathrm{m}^{2}\right)$ is the luminance values at different locations of tunnel entrance section. $k$ is the reduction factor for luminance value, which can be usually confirmed according to the referred value listed in Table 3 . $L_{20}(\mathrm{~S})\left(\mathrm{cd} / \mathrm{m}^{2}\right)$ is the luminance value outside the tunnel hole.

For example, if the luminance value outside the tunnel hole was set to $3000 \mathrm{~cd} / \mathrm{m}^{2}$ in present paper, and the traffic flow of the highway (one-way three-lane) was designed to be more than 2400 cars per hour, so the luminance reduction factors at three lanes of tunnel were $0.045,0.035$, and 0.022 as shown in the Table 3, respectively. Finally, the luminance values calculated by the Eq. (3) at three lanes of tunnel entrance section were equivalent to $135 \mathrm{~cd} / \mathrm{m}^{2}, 105 \mathrm{~cd} / \mathrm{m}^{2}$, and $66 \mathrm{~cd} / \mathrm{m}^{2}$, respectively.

\subsubsection{Evolution of the luminance profile}

Luminance profiles at the entrance section of tunnel were modeled and fitted by the experimental data. The evolutions of these profiles should be evaluated and compared to the luminance curve lighted by conventional power, as proposed in the professional industry standard of "Specifications for Design of Ventilation and Lighting of Highway Tunnel" (JTJ026.1-1999) ${ }^{14)}$ (Figure 4).

\subsubsection{Luminance uniformity}

As mentioned earlier in present paper, due to the influence of highway project cost, only an existed semitransparent entrance section at the left side of tunnel

Table 3 Referred values of luminance reduction factors at the entrance section of tunnel

\begin{tabular}{|c|c|c|c|c|c|}
\hline \multirow{2}{*}{ Designed traffic flow $N(\mathrm{cars} / \mathrm{h})$} & \multicolumn{4}{|c|}{$k$} \\
\cline { 3 - 6 } & \multicolumn{4}{|c|}{ Vehicle speed $V_{\mathrm{t}}(\mathrm{km} / \mathrm{h})$} \\
\hline One-way two-lane & Two-way two-lane & 100 & 80 & 60 & 40 \\
\hline$\geq 2400$ & $\geq 1300$ & 0.045 & 0.035 & 0.022 & 0.012 \\
\hline$\leq 700$ & $\leq 360$ & 0.035 & 0.025 & 0.015 & 0.01 \\
\hline
\end{tabular}


Table 4 Referred values of luminance uniformity $\left(U_{0}\right)$ on the roadway

\begin{tabular}{|c|c|c|}
\hline \multicolumn{2}{|c|}{ Designed traffic flow $N($ cars/h) } & \multirow{2}{*}{$U_{0}$} \\
\hline One-way two-lane & Two-way two-lane & \\
\hline$\geq 2400$ & $\geq 1300$ & 0.4 \\
\hline$\leq 700$ & $\leq 360$ & 0.3 \\
\hline
\end{tabular}

was allowed to implement the natural light lighting scheme. Therefore, it's necessary to evaluate the luminance uniformity at the transverse direction of tunnel entrance section, so that to judge whether the 'zebra effect' was appeared in the current tunnel entrance section. Here, the luminance uniformity at different transverse sections of tunnel was defined as

$$
U_{\mathrm{x}}=L_{\mathrm{xmin}} / L_{\mathrm{xav}}
$$

where $U_{\mathrm{x}}$ is the luminance uniformity. Lxmin $\left(\mathrm{cd} / \mathrm{m}^{2}\right)$ is the minimum luminance value at one of transverse sections. $L_{\mathrm{xav}}\left(\mathrm{cd} / \mathrm{m}^{2}\right)$ is the averaged luminance value at the corresponding transverse section.

Table 4 listed the referred values of luminance uniformity $\left(U_{0}\right)$ on the roadway, which were also proposed by the professional industry standard of "Specifications for Design of Ventilation and Lighting of Highway Tunnel" (JTJ026.1-1999) $^{14)}$. As seen in the table, for the current case discussed in present paper, only when the luminance uniformity $\left(U_{\mathrm{x}}\right)$ calculated by the Eq. (4) was more than or equivalent to 0.4 , then the tunnel lighting would be considered no 'zebra effect' existed.

\section{Experimental results and analyses}

\subsection{Lighting luminance at the entrance section of tunnel}

Measurements were done at three different operation conditions: at the time of 10:00 a.m., and the luminance outside tunnel hole was $940 \mathrm{~cd} / \mathrm{m}^{2}$; at the time of $12: 00$ a.m., and the luminance outside tunnel hole was $735 \mathrm{~cd} /$ $\mathrm{m}^{2}$; at the time of $15: 00 \mathrm{p} . \mathrm{m}$., and the luminance outside tunnel hole was $188 \mathrm{~cd} / \mathrm{m}^{2}$. It was seen that measured luminance values were not high due to the day's cloudy weather.

Figure 6 showed the evolutions of the averaged luminance tested at the entrance section as functions of luminance outside the tunnel hole. As seen in the figure, the tested luminance profiles lighted by the natural light could be synchronistically adjusted automatically based on the variations of the luminance values outside tunnel hole, and in the meantime, more gently decay evolutions were presented along the driving direction, especially for the earlier $20 \mathrm{~m}$ of tunnel entrance section, which indicated the design of natural light lighting scheme eliminated basically the 'black-hole effect' at the tunnel entrance. Furthermore, compared with the lumi-

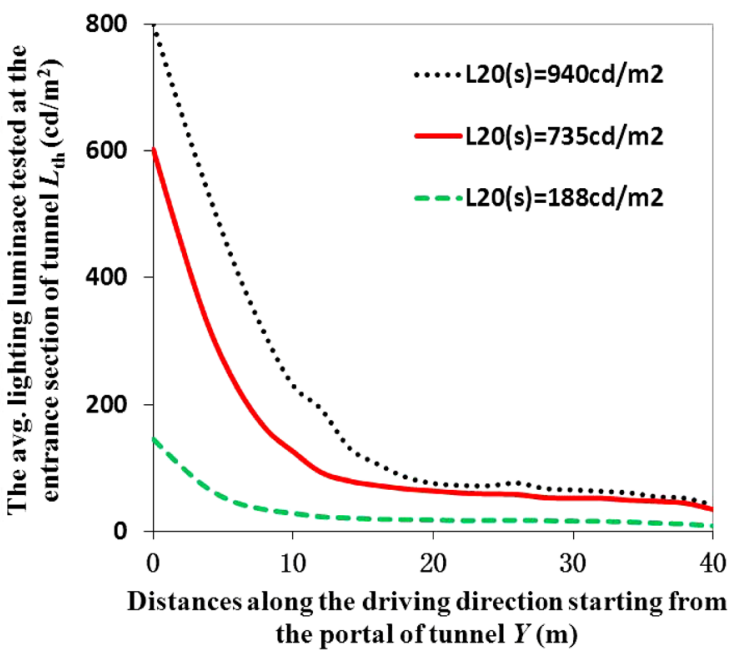

Figure 6 Evolutions of the averaged luminance measured at the entrance section as functions of luminance outside the tunnel hole.

Table 5 Comparisons of experimental and targeted luminance values

\begin{tabular}{cccc}
\hline $\begin{array}{c}\text { Luminance outside the } \\
\text { tunnel hole }\left(\mathrm{cd} / \mathrm{m}^{2}\right)\end{array}$ & $\begin{array}{c}\text { Experiments } \\
\left(\mathrm{cd} / \mathrm{m}^{2}\right)\end{array}$ & $\begin{array}{c}\text { Targets } \\
\left(\mathrm{cd} / \mathrm{m}^{2}\right)\end{array}$ & $\begin{array}{c}\text { Deviations } \\
\left(\mathrm{cd} / \mathrm{m}^{2}\right)\end{array}$ \\
\hline 940 & 41.8 & 32.9 & +8.9 \\
735 & 34.6 & 25.7 & +8.9 \\
188 & 8.5 & 6.6 & +1.9 \\
\hline
\end{tabular}

Notes: here, an avg. vehicle speed of $80 \mathrm{~km} / \mathrm{h}$ was suggested to confirm the reduction factor of luminance, and hence, a value of 0.035 was adopted to calculate the targeted luminance above.

nance curve lighted by the conventional electrical power (curve ' $b$ ' in the Figure 4), the decay rate of the current luminance profiles were much closer to the human visual adaption curve (curve ' $a$ ' in the Figure 4), which meant that the driver's visual fatigue could be significantly eased. Hence, the driving safety and amenity of the tunnel were improved.

In addition, the measured luminance values at the entrance section of tunnel were compared to the targeted values required by the tunnel project as shown in the Table 5. As mentioned earlier in present paper, here the targeted values were calculated by the Eq. (3). It can be seen that the measured luminance values at three different operation conditions satisfied the requirements of tunnel project, although the designed values were slightly higher than the targeted values. The plus deviations of luminance values could not be considered as wasting of energy, since the natural light applied in present paper was one of renewable energy actually.

\subsection{Lighting luminance at different lanes}

Measured lighting luminance profiles at three lanes of tunnel were shown in Figure 7. Due to the influences of weather and geographic positions, slight differences 


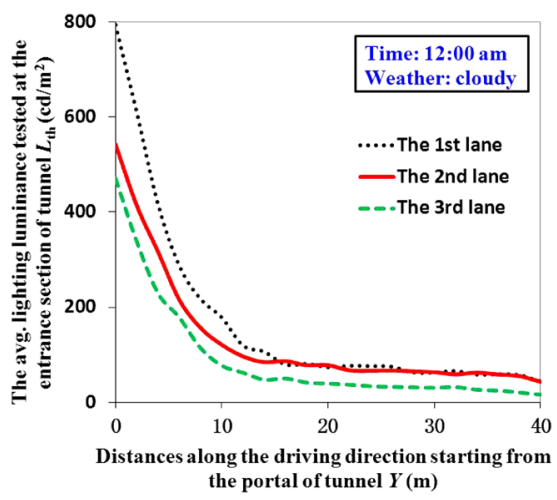

(a) Cloudy at 12:00 am

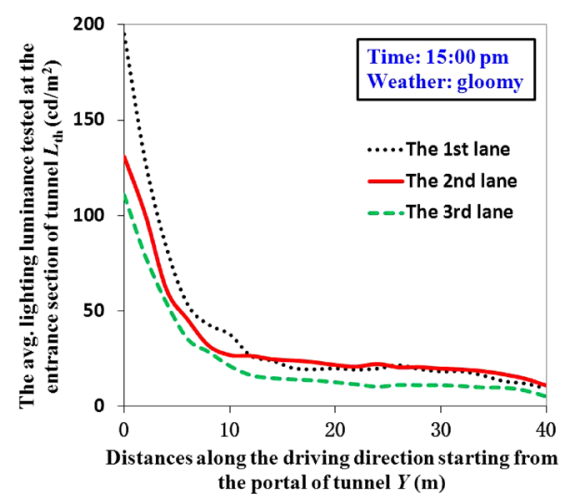

(b) Gloomy at 15:00 pm

Figure 7 Comparisons of lighting luminance profiles at different lanes of tunnel. (a) Cloudy at $12: 00$ a.m. (b) Gloomy at $15: 00$ p.m.

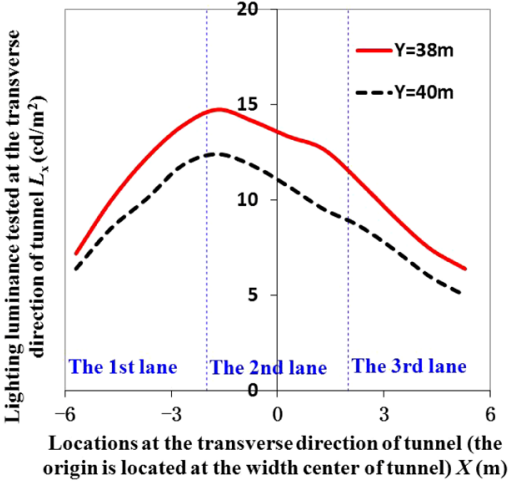

(a) Lighting luminance

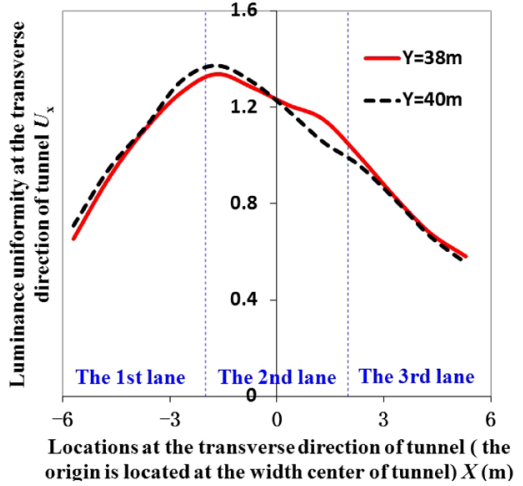

(b) Luminance uniformity

Figure 8 Distributions of lighting luminance and its uniformity at the transverse direction of tunnel entrance section. (a) Lighting luminance. (b) Luminance uniformity.

of luminance values at the entrance of tunnel were found among three lanes. However, this did not affect the analysis of the experimental results below.

As seen in the figure, due to the strong light-scattering behavior of the frosted glass, the lighting luminance at each lane decreased gradually according to the similar rhythm along the driving direction. Furthermore, evolutions and values of luminance between the first and second lanes were almost the same after the later $25 \mathrm{~m}$ of tunnel entrance section, while the same phenomenon was not observed at the third lane, the lighting luminance of the third lane was obviously lower. This problem could be explained by the design and installation positions of lighting glass. Since the lighting bands of natural light were located at the left side of tunnel and installed at the location between the first and second lanes, which was a little far away from the third lane. Hence, it could be understood easily that the light scattering behavior at the first and second lanes was much stronger than the third lane, so that the lighting luminance between the first and second lanes was higher.
Here, indications should be pointed out that, due to the influences of cost limitations, the potential of the natural light lighting technology had not been fully displayed on the present tunnel project. It was assumed that the lighting bands were designed and installed symmetrically at both sides of tunnel entrance section, the lighting uniformity among three lanes of the tunnel would be much better.

\subsection{Uniformity analysis of luminance}

In order to analyze the luminance uniformity at the transverse direction of tunnel, measurements were done at two different transverse sections. The first section located at the terminal of entrance section $(Y=40 \mathrm{~m})$, and the next was $2 \mathrm{~m}$ in vertical distance away from the terminal $(Y=38 \mathrm{~m})$. At each section, a total of 12 points with an interval distance of about $1 \mathrm{~m}$ was measured.

Figure 8 showed the experimental results of the luminance values and uniformity distributions at two transverse sections mentioned above. As seen in the 
figure, the shapes of luminance curves at two different transverse sections kept in same, and the corresponding uniformity distribution curves showed with an incompletely symmetric parabolic shape, were overlapped nearly. Furthermore, the peek value of the parabola was appeared at the locations between the first and second lanes, and the right hand side of the parabola (the luminance of the third lane) is slightly lower than the left hand side (the luminance of the first lane). The main reason of that was due to differences of the installation positions of lighting bands and the light scattering behavior of lighting glass, which had been already discussed yet in Figure 7, actually. In addition, the minimum values of luminance uniformity at two transverse sections were up to 0.55 or more, which were much higher than the referred value of 0.4 suggested in the Table 4. It could be concluded that the whole tunnel lighting distributed well in uniformity, no 'zebra effect' was observed.

\section{Conclusions}

Based on the considerations of energy-saving and emission reduction, a natural light lighting scheme was designed and applied to the tunnel entrance section of a highway. Results showed, (1) the natural light scheme eliminated essentially the 'black-hole effect' at the entrance of tunnel, which enhanced significantly the safety and amenity of driving in tunnel. (2) The scheme created considerable energy-saving and emission reduction of tunnel lighting. Compared with the conventional scheme lighted by the electrical power, although influenced by the limitations of the tunnel project cost, the yearly energy-saving rate of the present scheme was still beyond $40 \%$ or more, and the emission reductions of carbon dioxide and sulfur dioxide reached up to 123 tons and 3.7 tons per year, respectively. (3) The scheme was simple, practical, and reasonable in cost. Hence, it could be concluded that the application of natural light to the tunnel lighting engineering had significant engineering popularization values.

To further validate the practicality and reliability of the present scheme lighted by natural light at the entrance section of tunnel, experimental study were done to evaluate the application effect in the later paper. As the results, the designed lighting luminance at the entrance section of tunnel satisfied requirements of engineering, and furthermore, (1) compared to the conventional scheme lighted by electrical power, the lighting luminance profile of natural light decayed more gently, and its decay rate was much closer to the human visual adaption curve. Therefore, the 'black hole effect' at the entrance of tunnel was eliminated essentially, which enhanced significantly the driving safety and amenity in the tunnel road. (2) Due to the influences of lighting glass installation positions, the luminance values at the first and second lanes were obviously higher than the third lane, and in the meantime, the luminance uniformity between the first and second lanes were also better. (3) The distributions of luminance uniformity at different transverse sections of tunnel almost kept the same, and the minimum value of the luminance uniformity at each transverse section of tunnel was up to 0.55 , which indicated that the whole tunnel lighting distributed well in uniformity, no 'zebra effect' could be observed.

\section{Acknowledgements}

The authors acknowledge the Science Technology Plans of Hunan Province for supporting the project (2014FJ3038). Valuable discussion and help from Mr. Yanming Song at the Research and Promotion Center for Energy-saving and Emission Reduction Technology of Hunan Transportation, is also appreciated.

\section{References}

(1) The department of comprehensive planning of transportation of China ministry: The national highway network planning, http://www.chinahighway. com/fujian/guojiagasu.pdf (2004) (in Chinese).

(2) The department of comprehensive planning of transportation of China ministry: Bulletin of statistics for the Chinese transport industry development in 2011, http://www.moc.gov.cn/zhuzhan/ tongjigongbao/fenxigongbao/hangyegongbao/ 201204/t20120425_1231778.html (2011) (in Chinese).

(3) Peña-García, A., Gil-Martín, L. M.: Study of pergolas for energy savings in road tunnels comparison with tension structures, Tunnelling and Underground Space Technology, 35, pp.172-177 (2013).

(4) Fan, S., Yang, C., and Wang, Z.: Automatic control system for highway tunnel lighting, Computer and computing technologies in agriculture IV, Springer Berlin Heidelberg, pp. 116-123 (2011).

(5) Xia, Y.: Illumination problems in highway tunnels and their countermeasures, Western China Communication Science \& Technology, (1), pp. 5-6 (2008).

(6) Ren. J., Qu. Z, and Zhao. Q.: Practice and thinking on energy saving of tunnel lighting and power supply and distribution for expressway, China ITS Journal, (5), pp. 100-107 (2007).

(7) Yang, G.: The energy-saving plan about high pressure sodium lamp and some subsistent problems in the condition of reduction voltage, Light \& Lighting, (3), pp. 11-16 (2009).

(8) Yang, C. and Wang, Z.: Energy-saving Technology for Highway Tunnel Lighting [J], Modern Tunneling Technology, 47 (2), pp. 102-108 (2010). 
(9) Yao, Q., Cheng, D. and Lin, Y.: Design and discussion of white LEDs' application on tunnel lighting, China Light \& Lighting, (11), pp. 6-9 (2008).

(10) Wang, X. and Zhou, J.: The Application of stepless intelligent control system to LED illuminating brightness in city tunnel, Transportation Science \& Technology, (1), pp. 92-94 (2009).

(11) Nagai, S., Ishida S., and Shinji, M.: Energy-saving lighting system for road tunnel, Underground space use: analysis of the past and lessons for the future, Istanbul, Turkey, pp. 625-631 (2005).

(12) Han, Z.: Lamps layout method combined with natural light artificial light for tunnel, The China Patent: CN101614360 (2009).

(13) Song, Y., Yi, Q., and Li, Y.: Study of entrance and exit of energy-saving tunnel base on natural light automatic regulation lighting technology, China ITS Journal, pp. 116-119 (2011).
(14) The Professional Standards of People's Republic of China: JTJ026.1-1999 Specifications for design of ventilation and lighting of highway tunnel, Beijing: China Communications Press (2000).

(15) CIE Technical Report: Guide for the lighting of road tunnels and underpasses, CIE 88-2004 (2004).

(16) NDRC (National Development and Reform Commission): Long-term energy saving special planning of China, http://www.sdpc.gov.cn/rdzt/jsjyxsh/ t20050711_43529.htm (2004).

(17) Liu, S. and Qin, D.: Method of measurement of road lighting lights on the degree, Electric Engineering, (3), pp. 10-12 (2009).

*Corresponding author: 472\#, the 3rd Section of Furong Middle Road, Changsha, Hunan 410015, China. Tel: +86 0731-85164421(603); fax: +86 0731-85216472. E-mail address: wangbaolin2001@126.com 